\title{
CAPACITY COMPETITION IN DIFFERENTIATED OLIGOPOLIES: ENTRY DETERRENCE WITH ALTERNATIVE OBJECTIVE FUNCTIONS
}

Bojan Ristić, Dejan Trifunović, Tomislav Herceg

\section{Abstract}

This paper aims to identify the possible implications of quantity competition in markets with differentiated products on entry deterrence. If capacity commitments characterise this industry, quantities can be expected as the choice variable of rational players, even in the presence of product differentiation. Different equilibria of a static game occur depending on the degree of asymmetry of players, incumbent and entrant, which will crucially affect the shape of their best response functions. Asymmetry can stem from players' advantage in demand and costs, their different objective functions, or the first-mover advantage. We will analyse entry where incumbent maximises the weighted average of profit and revenue while entrant is maximising profit. The reduction of asymmetry may intensify competition in the industry and, consequently, reduce entry barriers. Our findings provide an insight that could be used for practical recommendations for conducting competition policy and other sector-specific regulations, where the introduction and higher intensity of competition are desirable.

Keywords: differentiated oligopoly, capacities, quantity competition, asymmetry of players, incumbent, entrant

JEL Classification: D43, L13, L21

\section{INTRODUCTION}

Entry into an industry is an essential aspect of industrial organisation. Empirical facts suggest that entry is a common phenomenon in many industries. Typically, in markets with established incumbents, entry is on a small-scale basis, and the survival rate of entrants is low. Thus, it is important to understand economic incentives for entry and how incumbents can use their position to block entry or force the entrant to leave the market.

When faced with the potential entrant, the incumbent should decide whether to block or allow the entry. This decision for the incumbent is easy when it can block entry by producing monopolistic output. More often, the incumbent should produce a larger quantity than the monopolist, and it needs excess capacities to
Bojan Ristić, PhD

Assistant Professor

Faculty of Economics, University of Belgrade

E-mail: bojan.ristic@ekof.bg.ac.rs

ORCID: 0000-0002-9883-8914

Dejan Trifunović, $\mathrm{PhD}$

Full Professor

Faculty of Economics, University of Belgrade

E-mail: dejan.trifunovic@ekof.bg.ac.rs

ORCID: 0000-0003-2125-8142

Tomislav Herceg, PhD (corresponding author) Assistant Professor

Faculty of Economics and Business,

University of Zagreb

E-mail: therceg@efzg.hr

Address: Trg J. F. Kennedyja 6, 10000 Zagreb

ORCID: 0000-0001-8869-6775 
achieve this objective. Of course, capacity serves the purpose only if it cannot be costlessly liquidated, making a credible commitment visible to the entrant in the sense of Dixit (1982). Hence, the capacity expansion before the potential entrance is a signal of entry deterrence. The other possible incumbent's strategy is presented in the model of Milgrom and Roberts (1982), where entrant does not know the incumbent's marginal cost and knows only the probability distribution for this random variable, while entrant's cost is common knowledge. If the incumbent has low cost, it will send a signal in the form of a low price to the entrant that its cost is low, preventing entry in this way. Also, there are other possible ways to prevent entry, such as sleeping patents, when incumbent patents the technology that it does not intend to use to prevent an entrant from its usage.

The capacity expansion as a tool for blocking entry is relevant in industries with large fixed capacities - like railways, airlines or the casino industry. In the airline industry, potential entry is more often deterred with limit-pricing in Milgrom and Roberts (1982) spirit than with capacity expansion. Sweeting, Roberts and Gedge (2020) study the behaviour of incumbent airlines in the US and find that when Southwest airlines (potential entrant) operates at airports that are on a certain route but do not operate on the route itself, incumbents see this as the potential threat of entry and react by price reductions. According to Goolsbee and Syverson (2008), these price cuts were up to $20 \%$, and Morrison (2001) determined that these price cuts lowered traveller's expenditures on air tickets by 3.3 billion USD in 1998. Sweeting, Roberts and Gedge (2020) determine in their model that incumbent airlines should use limit pricing rather than a capacity expansion to deter entry. This result is also confirmed by Masson and Shaanan (1982), who find that in 37 industries, incumbents use limit pricing more often than capacity expansion. However, empirical evidence of Snider (2009) and Williams (2012) suggests that incumbent airlines use capacity expansion to deter potential small-scale entry and limit pricing to deter potential large-scale entry.

The capacity expansion as a means for entry deterrence was identified by Crozet and Chassagne (2013) in French high-speed rail. Namely, the incumbent SNCF expanded the capacity by launching a highspeed train operator, Ouigo, that prevents potential entry into the low-cost service segment. Cherbonnier et al. (2017) assume that the monopolistic rail operator maximises the weighted average of its profit and consumer's surplus due to the exogenous regulatory constraints. This objective function explains the price distortion that exists in the monopoly market.
Moreover, this strategy may also reflect limit-pricing aimed at discouraging entry in the market since the monopolist who maximises this alternative objective function has a larger capacity and lower equilibrium price than the profit maximising monopolist.

The empirical analysis of predatory capacity expansion was limited because there was only a potential threat of entry in many industries. However, in the casino industry, the entry plans are apparent because the entrant has to make contracts with vendors and suppliers. Casinos compete in the size of the floor space, and vendors in the second stage compete in supplying casino machines and other products. Investments in the casino floor space are irreversible, and the capacity expansion represents a commitment to deter entry. This type of competition is similar to Kreps and Scheinkman (1983) two-stage competition that leads to one stage Cournot (1838) outcome. Cookson (2018) finds that incumbent casinos increase the floor space by 4 to $7 \%$ after the entry announcement. The higher demand did not trigger this capacity expansion since this would imply that the entry would be more likely to succeed upon incumbent's increase of capacities.

In contrast, Cookson (2018) finds that the likelihood of successful entry was reduced after the capacity expansion, which implies that the incumbent intended to deter entry. The second argument that capacity expansion was strategic can be inferred from the behaviour of casinos that were further from the entrant's planned location, and these casinos did not increase capacities like the nearby incumbent casinos. The third fact is that incumbents did not increase the capacity after entrants underwent construction works, which means that incumbents did not use larger capacities to accommodate entry but to prevent it.

In this paper, we will use the approach when the entry is blocked with excess capacities. The setup of our model is similar to Dixit $(1979,1980)$. We assume that there is one incumbent with a potential monopolistic position and one entrant. The firms sell differentiated products and are faced with linear demand functions. The incumbent has some initial level of capacities, and if it produces above this level, it should build additional capacities, and its marginal cost jumps to a higher level.

The contribution of our paper is to analyse entry when incumbent maximises the weighted average of profit and revenue. The evidence that justifies using this objective function can be found in practice since managers' compensations depend not only on the company's profit but also on the sales volume and consequently market share (measured by revenue). There are several possibilities for how a firm's size is measured: quantity produced, total revenue or market 
share (see Cornes and Itaya 2016). We have chosen total revenue as the measure of firm size since it is a standard measure of the company size and company classification (micro, small, medium, large) used in the European Union, CEFTA and most other countries. On the other hand, the entrant only maximises profit since its entry decision depends only on the sign of its profit (positive or negative).

If an entrant enters the market, the post-entry subgame can result either in Cournot or Stackelberg equilibrium. Since incumbent maximises the weighted average of profit and revenue in a Cournot equilibrium, it produces more than in equilibrium where both firms maximise profit, and entrant produces less. However, the total quantity produced is larger, and the average price for consumers is lower. In Stackelberg equilibrium, the incumbent produces a larger quantity than in the pure profit maximising equilibrium, while entrant produces less. As in the case of the Cournot mechanism, the total quantity produced is larger while consumers pay a lower average price.

We then consider the first stage of the game when incumbent can block or allow the entry. Compared to the standard situation of profit maximising firms, it is more likely that the incumbent can block entry by producing the quantity that maximises its alternative objective function, making entry less likely. Moreover, when entry occurs, the entrant chooses a smaller capacity level than in a pure profit maximising equilibrium.

The rest of the paper is organised as follows. In the second part, we provide the literature review about capacity expansion as a means of blocking entry. In the third part, we derive the equilibrium of the postentry subgame in the case of the alternative objective function of the incumbent, and in the fourth part, we analyse the incumbent's decision whether to block or to allow entry. In the last section, we conclude the discussion.

\section{LITERATURE REVIEW}

Entry deterrence with excessive capacities was analysed by Spence (1977) with the idea that investments in irreversible capacities represent a credible threat. In this model, the incumbent produces the monopoly output but invests in the large capacity to produce the competitive output. If entrant believes in that threat, he will not enter the market. According to Tirole (1988), the lower the depreciation rate of the capital and the more specific it is, the more credible is the commitment to deter entry with capacity expansion.
The considerable improvement of the entry deterrence model with capacities as a means for preventing entry is provided by Dixit (1979), where fixed costs of entry represent a barrier to entry. Figure 1 illustrates this model.

Figure 1. Capacity competition and entry deterrence with fixed costs

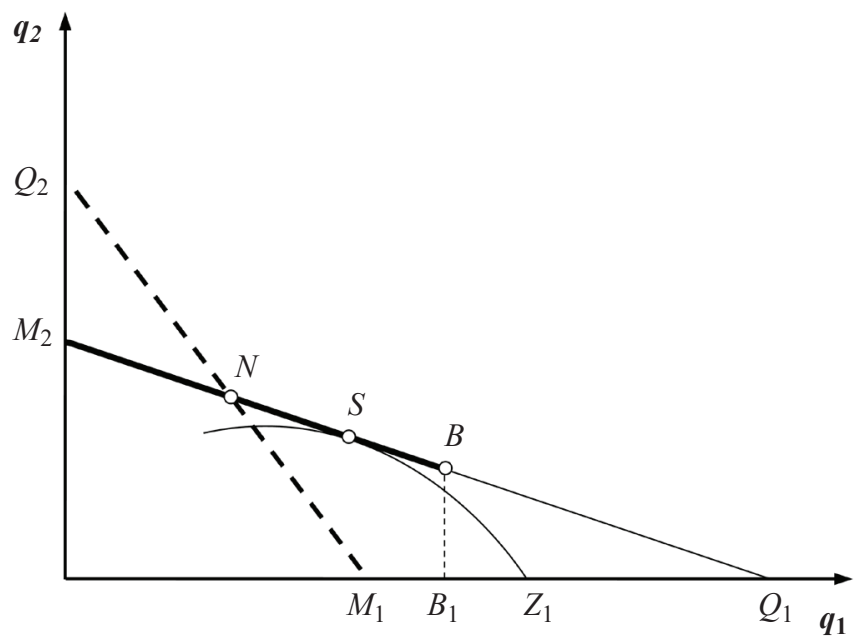

Source: Dixit, 1979

The line $M_{1} Q_{2}$ is the reaction function of the incumbent, and $M_{2} Q_{1}$ is the reaction function of the entrant. If the incumbent is the monopolist, it produces at point $M_{1}$. At $Q_{1}$, the entrant has zero production, and its profit is zero. The Cournot-Nash equilibrium is obtained at point $N$, while Stackelberg equilibrium is obtained at point $S$, where the incumbent is the leader, and the entrant is the follower.

If the entrant has fixed costs of entry, its profit becomes zero to the left of $Q_{1}$, for example, at point $B$, where the incumbent produces $B_{1}$. The exact position of $B$ depends on the level of fixed costs. When these costs are higher, this point moves to the origin. Entrant's reaction function contains two segments, $M_{2} B$ and the segment that coincides with the horizontal axis, $B_{1} Q_{1}$. If entrant's fixed costs are so high that the point $B_{1}$ is to the left of $M_{1}$, there is no possibility for entry, and the incumbent will produce the monopoly quantity.

The point $Z_{1}$ in Figure 1 is the quantity produced by the incumbent at the point where its iso-profit line trough point $S$ meets the horizontal axis. If entrant's fixed costs are small, such that $B_{1}$ is located to the right of $Z_{1}$, the incumbent will obtain a lower profit by preventing entry (incumbent would be on a higher iso-profit line). Hence, if $B_{1}>Z_{1}$, entry is allowed, and incumbent chooses point $S$ as the Stackelberg leader. As we have explained before, when $B_{1}<M_{1}$, 
the incumbent can prevent entry by producing the monopoly quantity. If $M_{1}<B_{1}<Z_{1}$, the incumbent can move from the iso-profit line through $S$ to the lower iso-profit line with larger profit by moving from $Z_{1}$ to $B_{1}$. In fact, the incumbent can prevent entry by producing slightly above $B_{1}$, which is the limit output that prevents entry.

Concerning the comparative statics in Dixit's (1979) model, any change of parameters that increases $B_{1}$ (for example, smaller entrant's fixed costs) makes entry more likely. Any change of parameters that increases $M_{1}$ and $Z_{1}$ makes entry less likely. One parameter in comparative statics is the absolute advantage of a firm: the difference between the intercept of the inverse demand function and marginal cost. The increase of the incumbent's absolute advantage increases $M_{1}$ while $B_{1}$ is unaffected, which makes entry less likely. The second parameter in the comparative statics analysis is the degree of product differentiation; when it is optimal for the incumbent to allow entry, its profit increases when products are more differentiated. When it is optimal for the incumbent to block entry by producing the limit output, its profit increases when products become less differentiated. The last result is intuitive; it is easier to prevent entry if the entrant has a similar product. Finally, Dixit (1979) demonstrates that entry is less likely when the incumbent has excess capacities.

Further discussion and some additional insights about entry were discussed by Dixit (1980). The incumbent has installed the capacity of $k_{1}$, where $r_{1}$ is the cost of capacity, $c_{1}$ is the marginal cost of producing one unit of output, and $F_{1}$ represent other fixed costs. If the incumbent produces up to the capacity, the total cost of the incumbent is:

$$
C_{1}=c_{1} x_{1}+r_{1} k_{1}+F_{1}
$$

If the incumbent produces above the capacity, it needs additional capacity, and its total cost is:

$C_{1}=\left(c_{1}+r_{1}\right) x_{1}+F_{1}$.

The entrant has no installed capacity, and its cost is $C_{2}=\left(c_{2}+r_{2}\right) x_{2}+F_{2} \quad$ (Notice the similarity with the previous expression of firm 1 costs). Hence, the incumbent's marginal cost jumps discontinuously at the capacity level $k_{1}$, and it has two reaction functions, as shown in Figure 2.

The reaction function $M_{1} Q_{2}$ is relevant if the incumbent has to increase the capacity above $k_{1}$, and the reaction function $M_{1}^{\prime} Q_{2}^{\prime}$ is relevant when the incumbent uses the capacity up to the level $k_{1}$. The entrant's reaction function is $M_{2} Q_{1}$. Suppose the initial
Figure 2. Capacity competition and entry deterrence

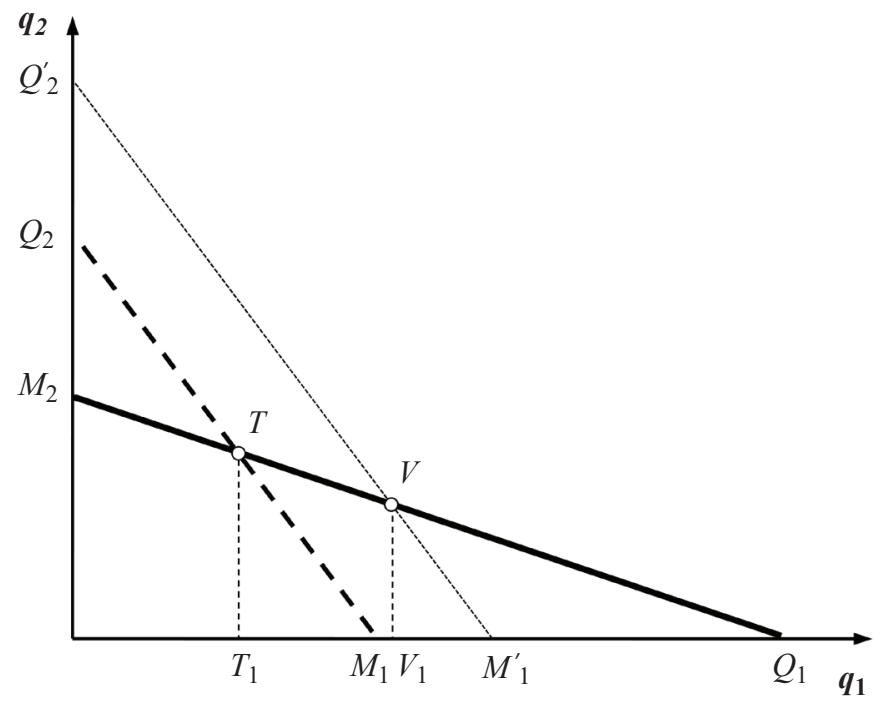

Source: Dixit, 1980

level of the incumbent's capacity is $k_{1} \leq T_{1}$. In that case, the equilibrium in the post-entry subgame is at $T$. If the initial level of incumbent's capacity is $k_{1} \geq T_{1}$, the equilibrium in the post-entry subgame is at $V$. If the initial level of incumbent's capacity belongs to the interval $T_{1} \leq k_{1} \leq V_{1}$, the equilibrium will be located on the $T V$ segment of the entrant's reaction function. The incumbent will fully employ the capacity such that $x_{1}=k_{1}$, while entrant will choose its production level as the Stackelberg follower for the given level of production of the leader.

The entrant's profit decreases when its production decreases. In Figure 2, the movement from $T$ to $V$ implies the reduction of entrant's profit. If entrant's profit is negative at $T$, then entry is not possible, and the incumbent will simply choose the monopoly production level at $M_{1}$. If entrant's profit is positive at $V$, the entry cannot be prevented. The incumbent will choose the production level where his iso-profit line is tangent to the entrant's reaction function on the $T V$ segment. If the tangency occurs to the right of $V$, the incumbent will be at point $V$ (the corner solution). If entrant's profit is positive at $T$ and negative at $V$, there is some point $B$ (like in Figure 1) on the line segment $T V$ where entrant's profit is 0 . At this point, the level of the incumbent's capacity is $B_{1}$, and if it sets the capacity above this level, it can prevent entry. If $B_{1}<M_{1}$, the incumbent can prevent entry by choosing the monopoly level of output. If $B_{1}>M_{1}$, the incumbent faces the trade-off. If its profit is higher when it blocks entry, it will choose the capacity level slightly above $B_{1}$. If its profit is higher when it allows entry, the incumbent will choose a point where its iso-profit line is tangent on the entrant's reaction function to the left of $B_{1}$. 
Dixit (1980) considers three extensions of the previous entry model. In the first extension, the entrant becomes the leader, while in the second, there is a discrete number of choices for the incumbent's initial capacity $k_{1}$. In the last extension, the post-entry subgame includes Bertrand competition with differentiated products. The graphical analysis is similar, but the reaction functions have a positive slope.

Dixit's (1980) model is extended by Schmalensee (1981) who assumes that instead of fixed entry cost, there is some minimum efficient scale of capacity, $k_{0}$, below which firms cannot profitably operate. Since the empirical evidence suggests that the efficient scale is typically lower than $10 \%$ of the aggregate demand in many industries, the efficient scale is not an effective barrier to entry.

The impact of uncertainty on the entry deterrence with capacities was studied by Maskin (1999), who introduced the mean preserving increase in the spread for the intercept of the inverse demand function. When demand is high, measured by the intercept of the inverse demand function, the incumbent produces at the level of capacity but could produce more if it had installed larger capacity. When demand is low, the incumbent produces at less than full capacity. Due to the capacity constraint, the increase in price for the higher realisation of demand intercept is larger in absolute value than the fall in price due to the low demand. Consequently, if entrant's profit is zero with no uncertainty, its expected profit is positive under uncertainty. To effectively deter entry, the incumbent should install a larger capacity under uncertainty than under certainty to equalise positive and negative price fluctuations for different realisations of demand and reduce entrant's profit to 0. Besides, Maskin (1999) concludes that with uncertainty compared to complete certainty, the incumbent is more likely to switch from the strategy of entry deterrence to the strategy of entry accommodation.

Huisman and Kort (2015) consider a similar setup with a linear demand function exposed to random shocks. When the uncertainty increases, the entrant waits for more to see the resolution of uncertainty, which leaves more time to the incumbent to benefit from a monopoly position. This increases the incentive for entry deterrence. Hence, the increase of uncertainty increases the likelihood of entry deterrence in this dynamic model of entry, in contrast to the static model of Maskin (1999).

The valuable extension of the entry deterrence model refers to the case with several incumbents considered by Gilbert and Vives (1986). In the first stage of the game, the incumbents decide on their capacity and production. In the second stage, the entrant decides to enter the market (and how much to produce) or stay out. The entrant has the fixed cost of entry, and all firms have the exact marginal costs. A certain level of output blocks entry and incumbents should decide whether to produce this output or to allow entry. With several incumbents, if one of them produces the entry deterring quantity, others might free ride on its decision, and entry deterrence becomes a public good. However, since marginal costs are constant and the profit of each incumbent increases with the production up to the level of output that blocks entry, all incumbents want to produce this output. The comparative statics result shows that when the number of incumbents increases, entry deterrence becomes more profitable for each incumbent compared to entry allowance.

\section{THE MODEL}

In our model, we will assume that firm 1 is the incumbent, and firm 2 is the entrant, and products are differentiated as in Dixit (1979) with the following system of inverse demand functions, where $p$ denotes price and $q$ quantity:

$$
\begin{aligned}
& p_{1}=\alpha_{1}-q_{1}-\gamma q_{2}, \\
& p_{2}=\alpha_{2}-q_{2}-\gamma q_{1} .
\end{aligned}
$$

The parameter $\gamma$ measures the degree of differentiation. When its value increases, products become less differentiated (more homogenous), and when its value decreases, products are more differentiated. This parameter measures cross-price effects, i.e. how the demand for one product changes when the price of its substitute changes. For the sake of simplification, it is assumed that the direct price effects are equal to 1 and that they are higher than the cross ones, so $0<\gamma<1$. Concerning the intercept of the inverse demand functions, $\alpha_{1}$, there are two possibilities. The first one is that both firms are symmetric, and the second, that there is a more significant willingness to pay for incumbent's products $\left(\alpha_{1}>\alpha_{2}\right)$ due to its established brand name. The symmetry in demand conditions will be assumed in this model.

The incumbent has the installed capacity of $k_{1}$ and other fixed costs of $F_{1}$. If it produces up to the installed capacity, it has the cost of each unit of capital equal to $r_{1}$, and the marginal cost for each produced unit of $c_{1}$. Formally,

$$
\bar{C}_{1}=r_{1} k_{1}+c_{1} q_{1}+F_{1} \text { for } q_{1}<k_{1} \text {. }
$$

If the incumbent produces above the installed capacity, its cost function becomes: 
$C_{1}=\left(r_{1}+c_{1}\right) q_{1}+F_{1}$ for $q_{1} \geq k_{1}$.

The entrant has no other options but to build the capacity for the intended scale of production, and its cost function is:

$C_{2}=\left(r_{2}+c_{2}\right) q_{2}+F_{2}$ for $q_{2}>0$.

We will assume that the entrant always maximises profit, and its objective function is given by:

$\pi_{2}=\left(\alpha_{2}-q_{2}-\gamma q_{1}\right) q_{2}-\left[\left(r_{2}+c_{2}\right) q_{2}+F_{2}\right]$

If the incumbent has the same objective function, we have the following two profit functions for the incumbent depending on whether it produces below or above the capacity level, respectively:

$$
\begin{aligned}
& \bar{\pi}_{1}=\left(\alpha_{1}-q_{1}-\gamma q_{2}\right) q_{1}-\left(r_{1} k_{1}+c_{1} q_{1}+F_{1}\right), \\
& \pi_{1}=\left(\alpha_{1}-q_{1}-\gamma q_{2}\right) q_{1}-\left[\left(r_{1}+c_{1}\right) q_{1}+F_{1}\right] .
\end{aligned}
$$

The contribution of our paper is to consider how different objective functions affect the entry game in this market. We will, therefore, assume that incumbent maximises the linear combination of profit and revenue, where the weight for the revenue is $\lambda$. We will assume that the level of capacities $k_{1}$ is the same as in the pure profit-maximizing equilibrium. A more involved analysis could include a higher level of capacities, $k_{1}^{\prime}>k_{1}$, when incumbent maximizes the alternative objective function. Thus, we have the following objective functions for the incumbent depending on how much capacity it uses:

$\bar{\Pi}_{1}=(1-\lambda)\left[\left(\alpha_{1}-q_{1}-\gamma q_{2}\right) q_{1}-\left(r_{1} k_{1}+c_{1} q_{1}+F_{1}\right)\right]$

$+\lambda\left(\alpha_{1}-q_{1}-\gamma q_{2}\right) q_{1}$,

$\Pi_{1}=(1-\lambda)\left[\left(\alpha_{1}-q_{1}-\gamma q_{2}\right) q_{1}-\left(\left(r_{1}+c_{1}\right) q_{1}+F_{1}\right)\right]$

$+\lambda\left(\alpha_{1}-q_{1}-\gamma q_{2}\right) q_{1}$.

The post-entry subgame can result in either Cournot or Stackelberg equilibrium, depending on the values of the parameters. Recall from Figure 2 that Cournot equilibrium at $T$ or $V$ is the corner solution of the Stackelberg equilibrium. We will first determine the Cournot equilibrium when both firms maximise profits as the benchmark case. From (8), we can obtain the incumbent's reaction function depending on the level of capacity it uses:

$$
\begin{aligned}
& \bar{R}_{1}\left(q_{2}\right)=\frac{\alpha_{1}-c_{1}}{2}-\frac{\gamma}{2} q_{2} ; \\
& R_{1}\left(q_{2}\right)=\frac{\alpha_{1}-c_{1}-r_{1}}{2}-\frac{\gamma}{2} q_{2} .
\end{aligned}
$$

The first reaction function is relevant when $q_{1}<k_{1}$, and the second one when $q_{1} \geq k_{1}$. It is evident that for $r_{1}>0$, the incumbent's reaction function when it produces less than $k_{1}$ is above its reaction function when it produces more than $k_{1}$. Therefore, the incumbent's reaction function is discontinuous at $k_{1}$, while entrant has the unique reaction function obtained by maximising its profit given by (7):

$$
R_{2}\left(q_{1}\right)=\frac{\alpha_{2}-c_{2}-r_{2}}{2}-\frac{\gamma}{2} q_{1}
$$

We have two Cournot equilibria, depending on the incumbent's production relative to its installed capacities. In the case of the incumbent's production, which leave excess capacities, at the intersection of functions $\bar{R}_{1}\left(q_{2}\right)$ and $R_{2}\left(q_{1}\right)$, the equilibrium corresponds to point $V$ in Figure 2 that can be defined as:

$\begin{aligned} q_{1}^{*} & =\frac{2\left(\alpha_{1}-c_{1}\right)+\gamma\left(c_{2}+r_{2}-\alpha_{2}\right)}{4-\gamma^{2}} ; \\ q_{2}^{*} & =\frac{2\left(\alpha_{2}-c_{2}-r_{2}\right)+\gamma\left(c_{1}-\alpha_{1}\right)}{4-\gamma^{2}} .\end{aligned}$

On the other hand, at the intersection of functions $R_{1}\left(q_{2}\right)$ and $R_{2}\left(q_{1}\right)$, the equilibrium, which corresponds to point $T$ in Figure 2, can be defined as:

$q_{1}^{*}=\frac{2\left(\alpha_{1}-c_{1}-r_{1}\right)+\gamma\left(c_{2}+r_{2}-\alpha_{2}\right)}{4-\gamma^{2}} ;$

$q_{2}^{*}=\frac{2\left(\alpha_{2}-c_{2}-r_{2}\right)+\gamma\left(c_{1}+r_{1}-\alpha_{1}\right)}{4-\gamma^{2}}$.

If the post-entry subgame results in a Stackelberg equilibrium, as in point $S$ in Figure 1, the incumbent as the leader $(l)$ will maximise its profit by choosing the point where his lowest iso-profit line is tangent to entrant's reaction function given by (11). Therefore, in the subgame perfect equilibrium, we have the following quantities for the leader and the entrant - as the follower $(f)$ in this game, respectively:

$q_{1}^{l}=\frac{2\left(\alpha_{1}-c_{1}-r_{1}\right)+\gamma\left(c_{2}+r_{2}-\alpha_{2}\right)}{4-2 \gamma^{2}} ;$

$q_{2}^{f}=\frac{4\left(\alpha_{2}-c_{2}-r_{2}\right)+\gamma\left[2\left(c_{1}+r_{1}-\alpha_{1}\right)+\gamma\left(c_{2}+r_{2}-\alpha_{2}\right)\right]}{8-4 \gamma^{2}}$.

In the post-entry Cournot equilibrium (the corner solution of the Stackelberg equilibrium), where the incumbent maximises the linear combination of profit and revenue given by (9), the incumbent's reaction functions depending on the level of its production are as follows:

$$
\begin{aligned}
& \bar{R}_{1}^{\lambda}\left(q_{2}\right)=\frac{\alpha_{1}-c_{1}(1-\lambda)}{2}-\frac{\gamma}{2} q_{2} ; \\
& R_{1}^{\lambda}\left(q_{2}\right)=\frac{\alpha_{1}-c_{1}(1-\lambda)-r_{1}(1-\lambda)}{2}-\frac{\gamma}{2} q_{2} .
\end{aligned}
$$


The first reaction function is relevant when $q_{1}<k_{1}$, and the second one when $q_{1} \geq k_{1}$. It is evident that the quantity produced by incumbent increases with $\lambda$ - the relative importance of revenue to profit in its objective function. Hence, when $\lambda$ increases, both versions of the incumbent's reaction functions given by (15) move upward, which is intuitive since it becomes more critical for the incumbent to maximise revenue than profit. Just in the original setting with $\lambda=0$, we have two equilibria depending on the incumbent's production level. From the intersection of $\bar{R}_{1}^{\lambda}(q 2)$ and $R_{2}\left(q_{1}\right)$ we have (notice that the reaction function of Firm 2 remains unaffected by alterations related to firm 1 objective function):

$q_{1}^{\lambda^{*}}=\frac{2\left[\alpha_{1}-c_{1}(1-\lambda)\right]\left(\alpha_{1}-c_{1}\right)+\gamma\left(c_{2}+r_{2}-\alpha_{2}\right)}{4-\gamma^{2}} ;$

$q_{2}^{\lambda^{*}}=\frac{2\left(\alpha_{2}-c_{2}-r_{2}\right)+\gamma\left[c_{1}(1-\lambda)-\alpha_{1}\right]}{4-\gamma^{2}}$.

Furthermore, from the intersection of $R_{1}^{\lambda}(q 2)$ and $R_{2}\left(q_{1}\right)$ we have:

$q_{1}^{\lambda^{*}}=\frac{2\left[\alpha_{1}-c_{1}(1-\lambda)-r_{1}(1-\lambda)\right]+\gamma\left(c_{2}+r_{2}-\alpha_{2}\right)}{4-\gamma^{2}} ;$

$q_{2}^{\lambda^{*}}=\frac{2\left(\alpha_{2}-c_{2}-r_{2}\right)+\gamma\left[c_{1}(1-\lambda)+r_{1}(1-\lambda)-\alpha_{1}\right]}{4-\gamma^{2}}$.

By checking the sign of derivatives with respect to $\lambda$ or, just, by the simple comparison of (16) and (17) with (12) and (13), respectively, it is evident that the quantity produced by the incumbent is always larger than in equilibrium when it maximises profit, while the entrant is producing less. Moreover, the increase of the incumbent's quantity is more significant than the fall of entrant's quantity, which means that the total quantity produced increases. As a result, the average price of incumbent and entrant's products is declining with the increase of $\lambda$. All the mentioned comparative statics results indicate a more competitive industry than in a situation where both players maximise profits.

When we have the Stackelberg equilibrium in the post-entry sub-game where incumbent maximises the alternative objective function, the quantities produced by the two firms are:
Just as in the Cournot equilibrium, a similar comparative static analysis can be conducted for Stackelberg equilibrium. It is interesting to observe that the incumbent's quantity produced increases with $\lambda$, which means that incumbent who maximises the alternative objective function produces a larger quantity than the incumbent who maximises profit. On the other hand, the entrant produces a lower quantity than in the benchmark model of profit maximisation. The result of these opposing movements is the increase in the total quantity produced in the Stackelberg industry. Formally $\partial\left(q_{1}^{\lambda l}+q_{2}^{\lambda f}\right) / \partial \lambda>0$, which is always the case for positive values of $c_{1}$ and $r_{1}$, and for the $0<\gamma<1$. Based on the same assumptions, the average price of leader's and follower's products decreases with the increase of $\lambda$, which has a positive influence on consumer surplus and the competition conditions in this industry.

\section{INCUMBENT'S DECISION AND $\lambda$ VALUE}

The value of $B_{1}$ from Figure 1 is obtained at the intersection of entrant's iso-profit line when long-run profit is precisely zero and its reaction function. The following expression shows that $B_{1}$ is invariant to the changes of $\lambda$.

$B_{1}=\frac{\alpha_{2}-c_{2}-r_{2}-2 F_{2}^{1 / 2}}{\gamma}$

However, when the incumbent produces above capacities, the monopoly outcome is obtained from $R_{1}^{\lambda}$ for $q_{2}=0$.

$M_{1}^{\lambda}=\frac{\alpha_{1}-c_{1}(1-\lambda)-r_{1}(1-\lambda)}{2}$

For $\lambda=0$ expression (20) reduces to $M_{1}=\left(\alpha_{1}-c_{1}-r_{1}\right) / 2$, which is identical to $M_{1}$ from Figure 2 . For all other values of $\lambda$ in the range $0<\lambda<1$, we have $M_{1}^{\lambda}>M_{1}$. Similar conclusions could be reached for the monopoly outcome when the incumbent's production is below installed capacities, which is obtained from $\bar{R}_{1}^{\lambda}$ for $q_{2}=0$ as:

$M_{1}^{\lambda}=\frac{\alpha_{1}-c_{1}(1-\lambda)-r_{1}(1-\lambda)}{2}$

$$
\begin{aligned}
& q_{1}^{\lambda l}=\frac{2\left[\alpha_{1}-c_{1}(1-\lambda)-r_{1}(1-\lambda)\right]+\gamma\left(c_{2}+r_{2}-\alpha_{2}\right)}{4-2 \gamma^{2}} ; \\
& q_{2}^{\lambda f}=\frac{4\left(\alpha_{2}-c_{2}-r_{2}\right)+\gamma\left[2\left(c_{1}(1-\lambda)+r_{1}(1-\lambda)-\alpha_{1}\right)+\gamma\left(c_{2}+r_{2}-\alpha_{2}\right)\right]}{8-4 \gamma^{2}} .
\end{aligned}
$$


Evidently, with the introduction of $\lambda$ into the model, we have positive shifts of both monopoly outcomes based on the incumbent's alternative reaction functions given by (15).

We have shown that the point $M_{1}^{\lambda}$ is to the right of $M_{1}$, while the position of $B_{1}$ is unaffected, which implies that it is more likely that entry could be blocked with $M_{1}^{\lambda}$, when $M_{1}^{\lambda}>B_{1}$. This makes entry more difficult since the incumbent can block entry by merely producing the quantity $M_{1}^{\lambda}$ that maximises its alternative objective function. This result is intuitive since incumbent cares not only about profit but also about the firm's size and is more willing to block entry than to allow it. Besides, the introduction of $\lambda>0$ also affects the price drop in the post-entry subgame for both Cournot and Stackelberg equilibrium, thus reducing the profit attractiveness of entry for the new competitor.

\section{CONCLUSION}

We have reconsidered Dixit $(1979,1980)$ model of preventing entry with capacity expansion. The contribution of our approach is to assume different objective function for the incumbent, consistent with contemporary principal-agent relationships, where managers pursue the objectives of profit maximisation and the increase of a firm's size. Entry in an industry under such conditions is more difficult since it is more likely that the incumbent can block entry by producing the quantity that maximises its alternative objective function. Our model might better explain recent empirical facts that entry is typically on a smallscale basis which coincides with our result that entrant's quantity falls when incumbent pursues the alternative objective function. Our model also explains the empirical fact that the survival rate of entrants is low. In an environment with massive incumbents that care about their profits and size, small entrants have a diminished likelihood of survival.

Our paper can be extended to study asymmetric firms when consumers have a higher willingness to pay for the incumbent's product. The other possible extension is to study the impact of product differentiation on the possibility of entry and the incumbent's profit in one or two-stage game contexts - where firms choose the product characteristics in the first stage and then compete in prices in the second stage. There is also the possibility to apply this model to some specific industries like in high-speed rails, where on-track capacity competition between incumbent and entrant is a recent phenomenon in some European countries. Entry of a new competitor and his survival upon entry is a major priority for the authority responsible for competition issues on highspeed rails. Yardstick competition models like this can monitor and eventually prevent incumbent's predatory behaviour in such industries as a precondition for imposing sustainable competition. The Infrastructure manager should use auction-based allocation of train paths to discourage incumbent's entry-deterring capacity expansion. Also, the government should organise auctions for public service obligation contracts instead of direct negotiations with the incumbent, which provides the additional possibility for preventing incumbent's capacity expansion.

Finally, our model can be validated empirically. However, it is challenging to identify entry intentions in some industries and to distinguish capacity expansion due to the larger demand, from capacity expansion aimed at entry deterrence. All these possibilities open a variety of possibilities for further research.

\section{REFERENCES}

Cherbonnier, F., Ivaldi, M., Muller-Vibes, C., and Van Der Straeten, K. 2017. Competition for versus in the market of long-distance passenger rail services. Review of Network Economics 16 (2): 203-238.

Cookson, J. A. 2018. Anticipated entry and entry deterrence: Evidence from the American casino industry. Management Science 64 (5): 2325-2344.

Cornes, R., Itaya, J. 2016. Alternative objectives in an oligopoly model: An aggregative game approach. CESifo working paper no. 6191.

Cournot, A. 1838. Researches into the Mathematical Principles of the Theory of Wealth. New York: The Macmillan Company.

Crozet. Y., and Chassagne, F. 2013. Rail access charges in France: Beyond the opposition between competition and financing. Research in Transportation Economics 39 (1): 247-254.

Dixit, A. 1979. A model of duopoly suggesting a theory of entry barriers. The Bell Journal of Economics 10 (1): 20-32.

Dixit, A. 1980. The role of investment in entry-deterrence. The Economic Journal 90 (357): 95-106.

Dixit, A. 1982. Recent developments in oligopoly theory. American Economic Review 72 (2): 12-17.

Gilbert, R., Vives, X. 1986. Entry deterrence and the free rider problem. The Review of Economic Studies 53 (1): 71-83.

Goolsbee, A., Syverson, C. 2008. How do incumbents respond to the threat of entry? Evidence from the major airlines. Quarterly Journal of Economics 123 (4): 1611-1633.

Huisman, K. J., Kort, P. M. 2015. Strategic capacity investment under uncertainty. The RAND Journal of Economics 46 (2): $376-408$. 
Kreps, D. M., Scheinkman, J. A. 1983. Quantity precommitment and Bertrand competition yield Cournot outcomes. The Bell Journal of Economics 14 (2): 326-337.

Maskin, E. S. 1999. Uncertainty and entry deterrence. Economic Theory 14 (2): 429-437.

Masson, R. T., Shaanan, J. 1982. Stochastic-dynamic limiting pricing: An empirical test. The Review of Economics and Statistics 64 (3): 413-422.

Milgrom, P., Roberts, J. 1982. Limit pricing and entry under incomplete information: An equilibrium analysis. Econometrica 50 (2): 443-459.

Morrison, S. A. 2001. Actual, adjacent, and potential competition estimating the full effect of Southwest Airlines. Journal of Transport Economics and Policy 35 (2): 239-256.

Schmalensee, R. 1981. Output and welfare implications of monopolistic third-degree price discrimination. American Economic Review 71 (1): 242-247.
Snider, C. 2009. Predatory incentives and predation policy: the American Airlines case (manuscript). Department of Economics. UCLA.

Spence, M. 1977: Entry, capacity, investment and oligopolistic pricing. The Bell Journal of Economics 8 (2): 534-544.

Sweeting, A., Roberts, J. W., Gedge, C. 2020. A model of dynamic limit pricing with an application to the airline industry. Journal of Political Economy 128 (3): 1148-1193.

Tirole, J. 1988. The Theory of Industrial Organization. Cambridge, MA: MIT Press.

Williams, J. W. 2008. Capacity investments, exclusionary behavior, and welfare: A dynamic model of competition in the airline industry. Empirical Studies of Firms \& Markets. 